\title{
Opportunities and Challenges for the Industrial Titanium Market
}

\author{
Hershel Robert (Rob) Henson
}

\author{
Manager, Business Development
}

VSMPO Tirus US

\begin{abstract}
The industrial titanium market is the second largest segment of the titanium industry and currently comprises less than $20 \%$ of the overall titanium market. In spite of a more than 50 year history of successful application in corrosive environments myths about availability, fabrication, pricing and corrosion resistance are still part of the conversation and culture with many potential customers. The author will discuss these issues and present comparisons with other common materials of construction to demonstrate the business case for titanium.
\end{abstract}

With seawater/brackish water being the most common corrosive environment where titanium is applied examples of current applications will be presented. By highlighting the characteristics of titanium that led to the material choice in these examples potential new applications can be identified. These examples will come from application on offshore platforms, LNG liquefaction plants, power generation, desalination and petroleum refining operations.

Against the backdrop of the application analysis the author will also explore regulatory, market influences and new technology impacting the industrial titanium market segment. Drawing on statistics from the Titanium Association and other resources a projection for industrial growth will be presented for the next decade.

My name is Rob Henson and I serve as the business development manager for VSMPO Tirus US, chairman of the International Titanium Association's (ITA) Industrial Applications Committee (IAC) and chairman of NACE Technology Exchange Group (TEG) $120 \mathrm{X}$ for reactive and refractory metals. VSMPO-Avisma Corporation is involved in the production and distribution of titanium mill products for aerospace, industrial, medical, and automotive applications. Titanium remains a strategic material of choice for demanding, high performance applications in aerospace, industrial and medical applications. 
As a global metal industry, titanium is small compared with the annual tonnages generated by steel and aluminum, yet titanium's inherent properties of light weight, high strength, corrosion and chemical resistance, and ability to operate in elevated temperatures make it an essential material for a spectrum of applications, from aerospace parts to industrial applications to medical components.

The industrial titanium market is the second-largest segment of the titanium industry in terms of market value. Important global industrial market sectors that utilize titanium include chemical and petro-chemical process industries, desalination, power generation, oil refining, natural gas processing and a broad swath of the petroleum industry from exploration to production. In spite of a more than 50-year history of successful application in corrosive environments, myths about availability, fabrication, pricing and corrosion resistance are still part of the conversation and culture with many potential customers.

My mission today in this presentation will be to discuss these issues and present comparisons with other common materials of construction to demonstrate the business case for titanium. Additionally, I will discuss the challenges faced by the industrial titanium market from both inside and outside of our industry. A very strong aerospace market is causing tightness in supply of raw materials and producers of competing materials for the corrosion market are tireless in their efforts to develop new specialty stainless alloys that can displace titanium on the basis of price.

\section{Challenges for Titanium in Industrial Applications}

While aerospace engineers talk about buy-to-fly ratios (the weight ratio between the raw material purchased and used for a component and the weight of the component itself), we have to convince clients that life-cycle cost savings related to long-term corrosion resistance, reliability and weight savings will make the business case for titanium. Unlike the aerospace market we cannot rely on high-temperature strength and low density to make our business case against competing materials.

In the industrial world we have to prove that the corrosion resistance of titanium, the mechanical properties in service, acceptance to industry codes, availability of all required products/components and the delivery of fabricated equipment to the job site will be the best solution for the customer needs. Each of 
these challenges is daunting in their own right, but together they make for a very formidable challenge. Once our customers are convinced to use titanium, and if it performs as expected, it opens the door for similar applications throughout the market. In this way we continually expand the use of titanium.

Each year the International Titanium Association-a membership-based international trade association dedicated to the titanium metal industry, established in 1984-organizes and hosts annual conferences in North America and Europe. That conference structure recently was extended to include Asia. These gatherings serve as an important forum for industry executives, stakeholders and research and marketing consultants to present their views on key trends and industry conditions. I'd like to offer feedback from recent conferences that can help outline the size and scope of the titanium industry (1):

- Longbow Research of Independence, Ohio, in 2018, estimated that Western World titanium demand is 118,000 metric tons to 120,000 metric tons, with global demand seen at 197,000 metric tons to 200,000 metric tons.

- Following are comments made concerning titanium industry supply chain and market conditions during the Titanium 2018 conference:

- David McCoy of TZ Minerals International of Australia said feedstock demand for titanium sponge reached 449,000 metric tons in 2018 and is expected to rise at compound annual growth rate of 5.3 percent through 2022 .

- Sylvain Gehler, chairman of UKTMP noted that world titanium sponge capacity in 2017 was rated at 255,300 metric tons, with China identified as the country with the largest sponge production capacity at 93,000 metric tons. Gehler also noted that the global average of sponge plant capacity utilization in 2018 was $77 \%$ and demand was expected to increase in 2019.

- Ed Newman, senior vice president, United Alloys and Metals Inc., said industrial demand for titanium scrap, estimated to be just over 30,000 metric tons in 2018, is expected to rise and then level off over the next three years to an annual level 
of around 35,000 metric tons. Scrap pricing and inventory levels typically are viewed as bellwether indicators for titanium industry business trends.

- Boeing projected that international commercial airlines will need 42,700 new jets during next 20 years, valued at $\$ 6.3$ trillion. Titanium is used for airframes, engine shrouds and internal engine parts, landing gear, and fasteners. Titanium Metals Corp., also known as Timet, using a composite of outlooks from Boeing, Airbus, Teal and Airline Monitor, estimated that titanium demand for commercial airframes will reach 45,000 metric tons in 2019 , compared with 40,000 metric tons in 2018.

- Industrial demand forecast provided by Albert Bruneau of NEOTISS

observed that titanium's competitiveness in industrial markets compared with alternative metals has been shaken with recent protectionist measures impacting negatively global aluminum, copper and nickel. These protectionist measures further complicate the task of predicting demand trends over the medium to long term.

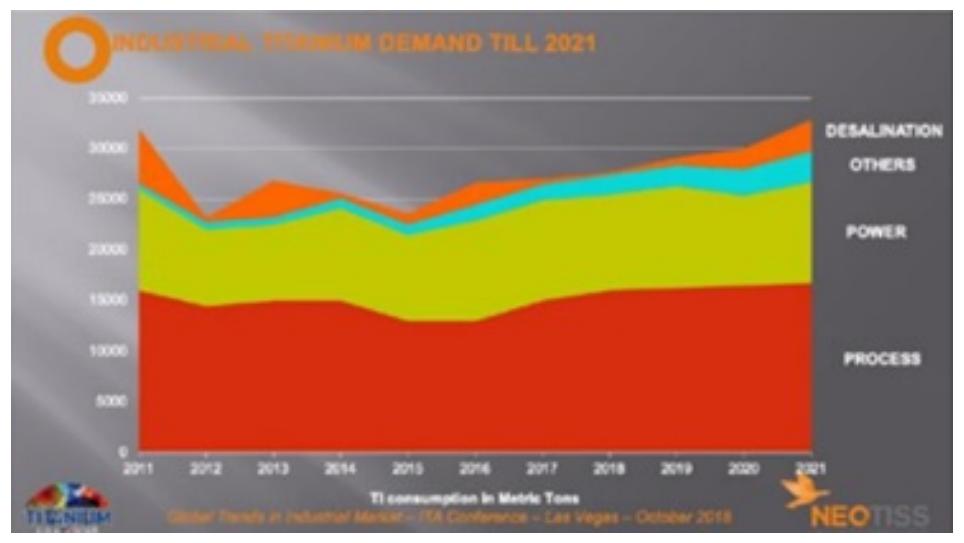

\section{Industrial Demand Trend 2011 through 2021}

An analysis of the preceding supply chain information suggests tightness in the market for titanium units starting at the oxide supply and continuing on through sponge and recycle. Further to his report on sponge capacity report Gehler commented on April 14,2019 that $90 \%$ capacity utilization is about the maximum sustainable level of plant operations. While this would seem to indicate available sponge capacity the situation 
of tightness of raw material for sponge as well as high prices of rutile will make it difficult for sponge producers to achieve a $90 \%$ usage of the capacity.

Previous experience with such market conditions have resulted in rising prices and allocation of mill products to strategic applications within the industrial market. These market trends are very disruptive to industrial market development as customers who have not planned well are suddenly forced to seek other solutions when titanium deliveries are pushed out beyond normal delivery times.

One final comment about the titanium supply chain and distribution of units across the market segments. The aerospace market is a higher value product, the customers currently have a 10 -year backlog and a 20 -year forecast valued at more than $\$ 6$ trillion. I can assure this audience that the aerospace customers are aware of the supply chain issues and securing titanium deliveries with long term agreements. With the industrial market being near "the back of the line" when titanium units are allocated, we can only counsel our customers to be thinking longer term about critical materials for their projects.

\section{Need to Attract End Users to the Conversation}

In an effort to disseminate information about the titanium industry across the full spectrum of market segments and interested parties the International Titanium Association has adopted a mission statement which reads:

The ITA's main mission is to connect the public interested in using titanium with specialists from across the globe who may offer sales and technical assistance.

To deliver on this mission the ITA hosts annual conferences in the United States and Europe together with a semi-annual event in Asia. During these events an industrial session is organized providing a stage for the discussion of industrial applications. The industrial sessions are organized by the Global Industrial Applications 
Committee (IAC) and our recent analysis of these events has revealed we are not attracting end users to our events; in essence, we are often talking to other producers and vendors to the industry.

In an effort to reach the process industry end user community the IAC has been collaborating with the NACE Technology Exchange Group (TEG120X) which hosts an annual session during NACE Corrosion USA. Over three years or participation in this forum we have seen an increase in attendance for the end user community. We believe this trend is the result of taking our message to a venue that is already well attended by the end users. With so much competition in the conference world we have to go where the customers are rather than try to add another event on their calendar.

\section{Challenges and Opportunities}

The World Corrosion Organization (2) estimates a US $\$ 2.5$ trillion annual cost of corrosion worldwide ( 3 to 4 percent of gross domestic product [GDP] of industrialized countries) reflecting in part that many decision makers in industry and government do not fully understand the consequences of corrosion or how critical (and costly) it is to control it. This is a call to action for our industrial market segment to continue educating decisions makers at every opportunity on the subject of life cycle costing. We must assure that purchase price is not the only factor considered in material selection and that cost of ownership over the life of the asset is fully understood.

Further evidence of this problem is highlighted in the NACE publication "Cost of Corrosion," (3) a report based on a two year study commissioned by the U.S. Federal Highway Administration in 1999. This near 20-year-old report unfortunately is still representative of the lack of good corrosion control across the full spectrum of the U.S. economy.

The report estimates the annual cost of corrosion to the U.S. economy at $\$ 276$ billion spread across five major sectors including infrastructure, utilities, transportation, production and manufacturing and government assets. For the purpose of our discussion today, I want to focus on production, manufacturing and infrastructure, which were estimated to cost the U.S. economy $\$ 17.6$ billion and $\$ 22.6$ billion, respectively. 
The production and manufacturing sector includes oil production, mining, petroleum refining, chemical and pharmaceutical production, agriculture and food processing. These are all industrial segments where we have proven titanium applications but material choice in many of these sectors continue to specify less corrosion resistant materials and suffer the consequences.

\section{Offshore Opportunities}

The infrastructure sector included highway bridges, gas pipelines, ships, aircraft, railroad cars and hazardous material transport. For this sector titanium is well established in aircraft, but hardly known in ships and the shipping industry is facing a major challenge with the sulfur cap 2020 regulations that will require either an exhaust gas scrubber or a switch to low sulfur fuel oil for the industry.

For these ship scrubbers it seems again that industry has overlooked nearly 30 years of corrosion research done by the Norwegian Offshore Oil Industry, which has resulted in a material selection standard $(4,5)$ for equipment exposed to seawater and sour oil or gas products. The first two years of scrubber construction has been done with a combination of stainless and specialty stainless steels, which are likely to suffer from crevice and microbial influenced corrosion (MIC) due to exposure to seawater. The corrosion data and standards were available to this industry, but decisions were made on price rather than reliability and safety and overall life cycle costs.

According to a 2017 report published by the Norwegian University of Science and Technology (6):

The ever-growing energy demand requires the exploration and the safe, profitable exploitation of unconventional reserves (such as those in the Arctic regions). The extreme environments of some of these unique prospects challenge the boundaries of traditional engineering alloys, as well as our understanding of the underlying degradation mechanisms that could lead to a failure. Despite their complexity, high-pressure and high- 
temperature, deep and ultra-deep, pre-salt, and Arctic reservoirs represent the most important source of innovation regarding materials technology, design methodologies, and corrosion control strategies.

High-strength materials, including low-alloy steel and corrosion-resistant alloys, are essential to overcome the materials hurdles associated with the production of hydrocarbons from unconventional reservoirs. A multitude of corrosion-resistant alloys are used in oilfield applications, including martensitic, austenitic, ferritic, duplex, and precipitation hardenable stainless steels, solution annealed and precipitation hardenable nickel alloys, as well as titanium, cobalt, and aluminum alloys.

Strengthening the close collaboration between industry and academia is essential to develop a multi-scale understanding of the compound microstructureenvironment interactions to lead to optimal environmentally assisted cracking resistance.

\section{Infrastructure Opportunities}

For aging and deteriorating concrete bridges and buildings a titanium solution (7) has been developed in research sponsored by the Perryman Company and conducted at Oregon State University. This is an excellent example of the kind of innovative, engineering work that drives the titanium industry. Christopher Higgins, the Cecil and Sally Drinkward Professor of Structural Engineering in the School of Civil and Construction Engineering at Oregon State University, was the 2015 the recipient of the International Titanium Association's (ITA) Titanium Application Development Award. Higgins, working with Perryman Co., Houston, PA, was cited for his role in developing a novel titanium application for repairing deteriorating reinforced concrete bridges. 
To prove the concept a laboratory capable of testing full scale concrete bridge beams was built on campus at Oregon State University. The laboratory is capable of producing and fracturing full scale beams and an environmental chamber was built to simulate freezing that thawing cycles to which bridges are exposed. Adoption of the titanium staple was greatly facilitated by these full scale test samples and the engineering data they provided.

\section{Experimental Work (gravity loads)}

- Full-scale tests with typical proportions and materials from legacy designs

- Shear specimens: 10 (3 control) \#2 TiABs

- Flexure specimens: 10 (3 control) \#5 TiABs

- Fatigue and freeze-thaw exposure: 3 ( 2 shear, 1 flexure)

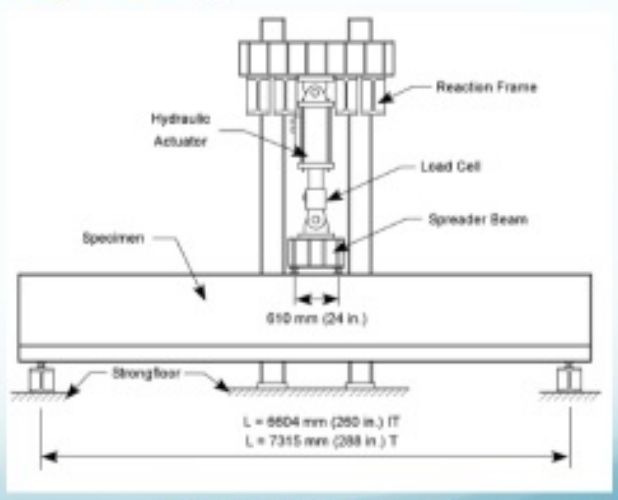

$4 \mathrm{ft} \mathrm{height,} 24 \mathrm{ft}$ long, $20,000 \mathrm{lb}$

\section{Schematic of full scale (1210mm height x 7315mm long, $9074 \mathrm{kgs})$ beam testing}

The Oregon Department of Transportation (ODOT), Salem, OR, selected a repair concept by Higgins - a titanium "staple" to reinforce fractures in the Mosier Bridge, an "overcrossing" of Interstate 84, which is a major east/west corridor for the state. Higgins designed the idea of the staple and the requirement of a surface treatment that would allow titanium alloy bars to be used to strengthen concrete bridges. 


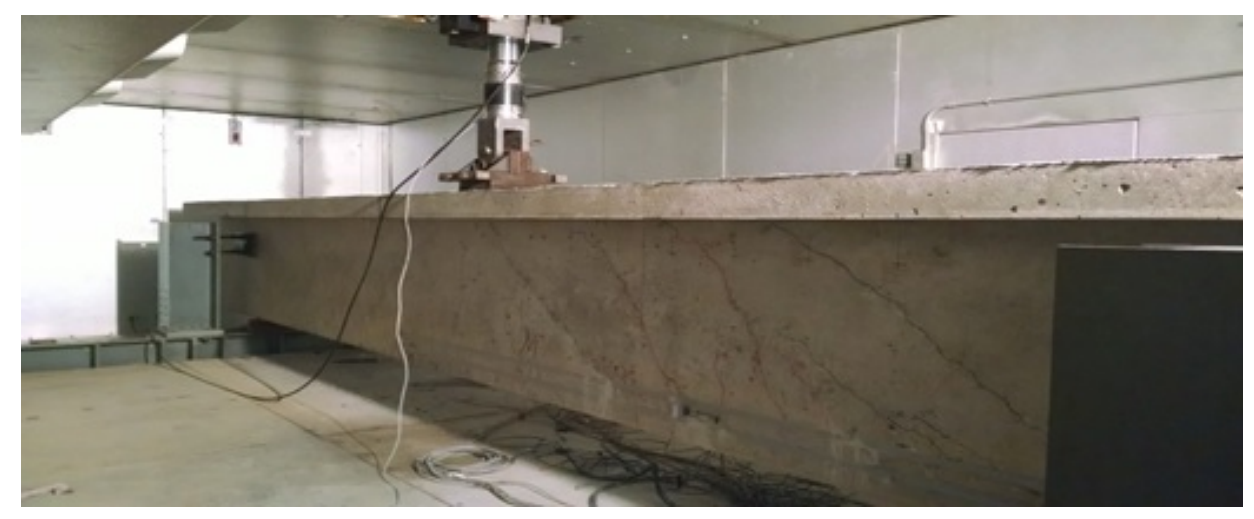

\section{Environmental test chamber}

The work that was done by Professor Higgins can open doors to additional infrastructure applications using titanium. Internationally, civil transportation infrastructure continues to age and deteriorate. Society has increased demands on these systems and requires them to carry higher volume, heavier loads, and remain inservice beyond their intended design life. Simultaneously, new and larger hazards have emerged from natural and manmade sources. Large investments are needed to maintain safety, mobility, and ensure continuous performance, yet replacement of existing assets is beyond fiscal reach.

Due to limited resources, strengthening, rehabilitation, and renewal of existing infrastructure have become necessary alternatives to replacement. Carbon-fiber reinforced polymers (CFRP) have become the material of choice for rehabilitation projects but have many drawbacks that can be overcome using titanium alloy bars. The titanium bar solution developed by Higgins is less costly than CFRP, has better environmental resistance and can be incorporated into a cathodic protection system to reduce the potential for corrosion of the existing steel bars in the structure.

Challenges to widespread acceptance of titanium alloy bars for civil infrastructure include the industry's ignorance of titanium's mechanical properties and long-term benefits, perception that the material is cost prohibitive, and lack of performance data for structures with titanium reinforcement.

\section{Price Competition}


In addition to the challenges of educating our potential customers, we will likely always be faced with lower cost for common engineering materials and competition for available titanium units. As a result we have to use titanium more efficiently by utilizing higher strength alloys, making sure that design codes are up to date and applying new technology to the manufacture of process equipment components.

The workhorse alloy of the aerospace market, Ti-6Al-4V, does not have a code case and cannot be used for the manufacture of pressure containing parts. This is a grade with a tremendous library of technical data and application history in the most demanding applications. Given the significant strength improvement and widespread production of this titanium grade, incorporation of Grade 5 into the production of process equipment should be viewed as synergistic to the overall industry, according to James McMaster of MC Consulting (4-02-19). Further additions to this value chain can be expected by the adoption of palladium containing Ti-6Al-4V Grade 24 to the code case which will greatly extend the corrosion resistance of the alloy.

Design codes for titanium process equipment were developed more than 40 years ago (8) and in many cases do not represent the quality of the metal produced in today's market. Going back to 1999 a consortium of interested parties realized that Grade 2 titanium design allowable was based on a minimum specified that was 20percent lower than 99 percent of the material currently being produced. This observation led to a code case proposing an increase in minimum UTS for titanium Grades $2 \mathrm{H}, 7 \mathrm{H}$ and $16 \mathrm{H}$ and a subsequent 16-percent increase in design allowable stress. This code case results in the application of less titanium to a given piece of pressure equipment and makes the titanium design more competitive against other materials of construction.

Division 1 essentially establishes minimum section thicknesses based on formulae and the allowable stresses found in Section II, Part D tables. Division 1 Allowable Stresses for titanium are based on UTS/3.5. This design method is used for vessels of the simpler designs or smaller vessels.

At the time the $\mathrm{H}$ grades were being created the ASME Section VIII Division 2 (9) of the pressure code was also under development. Finalization of Division 2 was 
complete before the $\mathrm{H}$ grades were finalized and as such $\mathrm{H}$ grades were not listed, and no one has requested the addition to Division 2.

Division 2 establishes section thickness based on either more sophisticated design formulae and/or allows Finite Element Analysis (FEA) to be used to more accurately define local stresses. Division 2 Allowable Stresses for Class 1 are based on UTS/3.0 and for Class 2 on UTS/2.4. The reduction in allowable stress is termed by ASME as a "Design Factor" ("Factor of Safety" in earlier practice). This method is used for complex designs or larger vessels.

As the $\mathrm{H}$ grades have not been included in the ASME Section VIII Division 2 design code there are further potential design efficiency that are not available at the present time. The Global Industrial Applications Committee (IAC) of the International Titanium Association is looking to develop a "joint industry program" composed of Chemical Processing Industry (CPI) companies, titanium fabricators and other interested parties working together to develop a "Code Case" for titanium "H" alloy grades to be included in the ASME's Section VIII, Division 2.

This Code Case would utilize the existing data for $2 \mathrm{H}$ that was used to generate the ASME Section VIII-Division 1, for calculation of the design allowable for Section VIII-Division 2. It has been estimated that by being able to use Titanium Grade $2 \mathrm{H}$ under ASME Division 2 requirements, the fabricator and the end user chemical process plant can realize significant savings by reducing the wall thickness of the pressure vessel.

One example estimates a yield savings in material use (due to a thinner wall thickness) up to 14 percent over the current Section VIII-Division 1 design allowable values and much more savings realized as compared to the current titanium Grade 2 values. This presentation will briefly review this joint industry program and what needed for the approval of titanium $2 \mathrm{H}$ grades (including $7 \mathrm{H}$ and $16 \mathrm{H}$ ) for use in the ASME Section VIII-Division 2 construction code. 


\section{NEXT STEPS IN ORDER TO OBTAIN ASME SECTION VIII, DIV. 2 APPROVAL}

- Obtain interested sponsors and participants

- Request user letter to ASME for a Section VIII-Div. 2, Class 1 and 2 Code Case

- User could be a fabricator or end-user which need to use Section VIII-Div. 2 rules for a titanium pressure vessel

- Use the original test data used when titanium Grade 2H was placed into Section VIII-Div. 1

\section{Plan outline for H Grade Div. 2 Code Case}

In addition to alloy development and updating design codes we have to look at incorporating new technology to the manufacture of process equipment components. Additive manufacturing incorporates the computer controlled application of energy to melt and accurately deposit solid metal to create components. These technologies offer a wide range of new design opportunities by allowing the creation of complex components that might otherwise have been made in multiple sections and the creation of bimetallic structures where a high strength alloy can be used as a base material and a more corrosion resistant metallic layer deposited on the surface which is exposed to the corrosive media.

Additive manufacturing, in recent years, has generated substantial interest in the titanium industry, however development efforts continue to unfold and challenges remain. Art Kracke, the president of AAK Consulting, who's been associated with the global titanium industry for four decades, said it's important to remember that additive manufacturing "is many technologies, not one thing. Additive manufacturing is an industry, not a single process."

Aerospace designers are weld depositing solid metal on plate substrates to create structures that would have previously been machined from much thicker plate, 
again a savings in metal and an additional savings in machining time.

While it is clear that pressure code design work will need to be pursued for the adaption of additive manufacturing produced components in pressure vessels, the motivation for those code cases seems significant-both to the end user and the titanium industrial market.

\section{Summary Remarks}

All the wonderful work being done in alloy development, design code updating and incorporation of new technology will not provide the anticipated results if we do not promote them. The promotion of industrial titanium application is dwarfed by the effort put forth by the stainless and nickel alloy industries. Together with the coatings industry our metal competitors leave little space for discussion of titanium. This is a most important challenge for our industrial market.

The World Titanium forum provides a tremendous technical platform for discussion of titanium every four years, but in large part we are talking to industry participants and not to our end user base. The Corrosion Solution Conference, which ran from 1999 to 2013 on a biannual basis, served as solid model for creating the stage that our industrial market needs. The IAC has acknowledged this as we face the same challenge when organizing industrial speaker tracks at our annual conferences.

In an effort to reach a broader audience, we have taken our message to other venues where process industry personnel are already attending. The Technology Exchange Group (TEG120X) reactive metals forum at NACE Corrosion allows for the exchange of technology in a less formal setting than that of a NACE symposium. This format makes organization of the meeting less time consuming and more flexible as to the inclusion of new topics or recent developments.

As current chair of both the ITA's IAC and the NACE TEG120X our teams are working to organize an additional stage for the discussion of industrial titanium which we see as complimentary to the work of TMS with World Titanium and we are hopeful you will consider participation with us to raise awareness of titanium in the industrial sector. It's in our mutual, strategic interest to cooperate in order for us to make progress. 
References

1. Jennifer Simpson, "Titanium USA 2018 Executive Summary", Titanium Today, Q4-2018, Issue 22, No.1, retrieved from URL: https://issuu.com/titaniumtoday/docs/titaniumtoday i22n1 powder $120118 \mathrm{w}$ ? $\underline{\mathrm{e}=34063458 / 66187732}$

2. George Hayes, "Now is the Time", retrieved from URL:

http://corrosion.org/Corrosion+Resources/Publications/ /nowisthetime.pdf

3. "Cost of Corrosion", NACE International, retrieved from URL:

https://www.nace.org/resources/general-resources/cost-of-corrosion-study

4. Jan Ivar Skar and Stein Olsen, "Development of the NORSOK M-001 and ISO 21457 Standards-Basis for Defining Materials Application Limits", NACE Corrosion 2016, paper 7433

5. ISO 21457, "Petroleum, petrochemical and natural gas industries - Materials selection

and corrosion control for oil and gas production systems"

6. Mariano lannuzzi, Afrooz Barnoush \& Roy Johnsen, "Materials and corrosion trends in offshore and subsea oil and gas production". Materials Degradation volume 1, Article number: 2 (2017) 
7. Christopher Higgins, Jonathan Knudtsen, Deanna Amneus \& Laura Barker. "Shear and Flexural Strengthening of Reinforced Concrete Beams with Titanium Alloy Bars" Proceedings of the 2nd World Congress on Civil, Structural, and Environmental Engineering (CSEE'17) Barcelona, Spain - April 2 - 4, 2017 Paper No. ICSENM 141 ISSN: 2371-5294 DOI: 10.11159/icsenm17.141

8. James McMaster \& Barry Greene, "A New Grade for Titanium", ASTM International, October 2006 retrieved from URL:https://www.astm.org/SNEWS/OCTOBER 2006/mcmgre oct06.html

9. Michael Gabriele, "ITA Committee Seeks to Update ASME 'code case" for Use of Titanium 'H' Grades in Pressure Vessels" MTI Connect, Winter 2019 retrieved from URL:https://www.mti-global.org/blogs/mti-forum/2019/02/11/mticonnect-the-first-issue 